\title{
Psychometric properties of the itch numeric rating scale, skin pain numeric rating scale, and atopic dermatitis sleep scale in adult patients with moderate-to-severe atopic dermatitis
}

Jonathan I. Silverberg ${ }^{1}$, Amy DeLozier² ${ }^{2 *}$, Luna Sun², Jacob P. Thyssen ${ }^{3}$, Brian Kim , Gil Yosipovitch ${ }^{5}$, Fabio P. Nunes ${ }^{2}$, P. Cristian Gugiu ${ }^{6}$, Helen A. Doll ${ }^{7}$ and Lawrence F. Eichenfield ${ }^{8,9}$

\begin{abstract}
Background: The Itch Numeric Rating Scale (NRS), Skin Pain NRS, and Atopic Dermatitis Sleep Scale (ADSS) are selfadministered patient-reported outcome (PRO) instruments developed to assess symptoms in patients with atopic dermatitis (AD). The objective of this study was to evaluate the psychometric properties (reliability, validity, and responsiveness) and interpretability thresholds of these PROs using data from three pivotal Phase 3 studies in adults.

Methods: BREEZE-AD1, BREEZE-AD2, and BREEZE-AD5 evaluated the safety and efficacy of baricitinib in adults with moderate-to-severe AD. Clinician-reported outcomes and other PROs commonly assessed in patients with AD were used to estimate meaningful changes and evaluate test-retest reliability, convergent and divergent validity, knowngroups validity, responsiveness, and meaningful change thresholds (MCTs) of the Itch NRS, Skin Pain NRS, and ADSS.

Results: The test-retest reliability of the Itch NRS, Skin Pain NRS, and ADSS was evidenced by generally large intraclass correlation coefficients (>0.7) in stable groups of patients between baseline and Week 1 and Weeks 4 and 8. Moderate-to-large correlations ( $r>0.4)$ at baseline and Week 16 were generally observed between each measure and other PROs measuring the same concept, supporting convergent validity. Small-to-moderate correlations with clinician-reported outcomes demonstrated divergent validity. Each instrument was able to distinguish between known groups of disease severity as assessed using other indicators of AD severity. The responsiveness of the Itch NRS, Skin Pain NRS, and ADSS scales was demonstrated through significant differences in their change scores from baseline to Week 16 between categories of change in another PRO also from baseline to Week 16. Thresholds for interpreting meaningful change were estimated as -4.0 for the $0-10$ Itch and Skin Pain NRS items; -1.25 for the 0-4 ADSS Items 1 and 3 and; -1.50 for the $0-29$ ADSS Item 2, these equivalent to moderate degrees of change.

Conclusions: Results of this study demonstrate that the psychometric properties of the Itch NRS, Skin Pain NRS, and ADSS are good to excellent. These findings support the use of these instruments in daily assessment of AD symptoms in adults with moderate-to-severe AD.
\end{abstract}

\footnotetext{
*Correspondence: delozier_amy@lilly.com
}

${ }^{2}$ Lilly Corporate Center, Eli Lilly and Company, Indianapolis, IN 46285, USA

Full list of author information is available at the end of the article permits use, sharing, adaptation, distribution and reproduction in any medium or format, as long as you give appropriate credit to the original author(s) and the source, provide a link to the Creative Commons licence, and indicate if changes were made. The images or other third party material in this article are included in the article's Creative Commons licence, unless indicated otherwise in a credit line to the material. If material is not included in the article's Creative Commons licence and your intended use is not permitted by statutory regulation or exceeds the permitted use, you will need to obtain permission directly from the copyright holder. To view a copy of this licence, visit http://creativecommons.org/licenses/by/4.0/. The Creative Commons Public Domain Dedication waiver (http://creativeco mmons.org/publicdomain/zero/1.0/) applies to the data made available in this article, unless otherwise stated in a credit line to the data. 
Trial registration ClinicalTrials.gov numbers: NCT03334396, NCT03334422, and NCT03435081.

Keywords: Atopic dermatitis, Atopic dermatitis sleep scale, Convergent-divergent validity, Itch NRS, Numeric rating scale, Patient-reported outcome, Psychometric, Reliability, Responsiveness, Skin pain NRS, Validity

\section{Background}

Patients with moderate-to-severe atopic dermatitis (AD) experience a heavy disease burden that substantially impacts both physical and mental functioning. Intense itch, skin pain, and related sleep disturbance are highly prevalent symptoms that patients with $\mathrm{AD}$ report as significantly affecting their quality of life (QoL) [1, 2]. The most commonly used instruments to assess the severity of AD include the Investigator Global Assessment (IGA) and the Eczema Area and Severity Index (EASI) [3-5]. These instruments are based on a physician's visual assessment of clinical signs, and thus fail to capture the patient-experienced symptoms of itch, skin pain, and their impact on sleep. Though itch, skin pain, and sleep disturbance are important to patients with $\mathrm{AD}$, measurement of these burdensome symptoms in clinical trials has so far been limited. Specific patient-reported outcome (PRO) measures may be useful to understand the burden from these symptoms better.

The Itch Numeric Rating Scale (NRS), Skin Pain NRS, and Atopic Dermatitis Sleep Scale (ADSS) are PROs designed to specifically measure the severity of a patient's itch and skin pain, and assess impact of itch on sleep, respectively. These tools were developed according to the Food and Drug Administration (FDA) PRO guidelines [6], as simple, self-administered assessments in daily electronic diaries used in AD clinical trials. Previous studies found that the Itch NRS, Skin Pain NRS [7], and ADSS had good content validity, i.e. represent aspects of disease that are meaningful to patients. However, the psychometric properties of each measure were not assessed. Instruments can assess clinically relevant information, but not have sufficient validity, reliability, or interpretability to be used in clinical trials or practice. These psychometric properties are needed to support the use of these measures in clinical trials. The objective of this study was to determine the reliability, validity, responsiveness, and meaningful change of the Itch NRS, Skin Pain NRS, and ADSS in patients with moderate-to-severe AD using data from three Phase 3 clinical trials.

\section{Methods}

\section{Study population}

BREEZE-AD1 (AD1), BREEZE-AD2 (AD2), and BREEZE-AD5 (AD5) were three multicenter, randomized, double-blind, placebo-controlled, parallel-group
Phase 3 clinical trials that evaluated the safety and efficacy of once daily, oral baricitinib $1 \mathrm{mg}$, and $2 \mathrm{mg}$, and $4 \mathrm{mg}$ (in $\mathrm{AD} 1$ and $\mathrm{AD} 2$ only) versus placebo in adult patients with moderate-to-severe $\mathrm{AD}$. In each trial, patients were $\geq 18$ years old and intolerant or inadequate responders to topical therapy. At screening and baseline, patients were required to have an EASI score $\geq 16$, a validated Investigator Global Assessment for Atopic Dermatitis (vIGA-AD ${ }^{\mathrm{TM}}$ ) score $\geq 3$, and a body surface area (BSA) involvement $\geq 10 \%$. Full details of each study, including the primary efficacy and safety outcomes, have been reported previously $[8,9]$. Each study was conducted with informed consent, under institutional review board approval, and in accordance with the Declaration of Helsinki (ClinicalTrials.gov numbers: NCT03334396 (AD1), NCT03334422 (AD2), and NCT03435081 (AD5)).

\section{Instruments used in the psychometric analyses Itch NRS, Skin Pain NRS, ADSS}

The Itch NRS is a single item designed to capture information on self-reported severity of worst itching each day. Patients were asked to rate itching severity based on the worst level of itching in the past $24 \mathrm{~h}$ using an 11-point scale from 0 ("no itch") to 10 ("worst itch imaginable"). The single-item Skin Pain NRS assesses selfreported severity of worst skin pain each day. For this, patients were asked to select a number from 0 ("no pain") to 10 ("worst pain imaginable") that best described the worst level of skin pain in the past $24 \mathrm{~h}$. The three-item ADSS captures self-reported impact of itch on sleep disturbance each day, including: difficulty falling asleep (Item 1); number of night-time awakenings (Item 2) and; difficulty falling back asleep after waking (Item 3) during the previous night. Each ADSS item was scored individually. For Items 1 and 3, patients were asked to select a score ranging from 0 ("not at all") to 4 ("very difficult"). For Item 2, patients selected the number of times they woke up each night, ranging from 0 to 29 times. Patients only answered Item 3 if their answer to Item 2 was greater than 0 . These three PROs were self-assessed using a daily electronic diary, starting at screening through Week 16. Information was entered into the electronic diary at the end of each patient's day. For each measure, weekly mean scores using the previous 7 days were calculated if at least 4 of the 7 diary values were non-missing. Weekly averages were calculated at baseline (Week 0 ) and Weeks 1, 2, $4,8,12$, and 16 . 


\section{Other scales}

The PROs used to evaluate the psychometric properties of the Itch NRS, Skin Pain NRS, and ADSS included: (1) the Dermatology Life Quality Index (DLQI) [10], a selfreported measure of the impact of AD on QoL; (2) the Patient Oriented Eczema Measure (POEM) (11), a selfassessed disease severity score; and (3) the Patient Global Impression of Severity-Atopic Dermatitis (PGI-S-AD). More specifically, the PGI-S-AD is a single item asking patients to rate their overall AD symptoms over the last $24 \mathrm{~h}$, ranging from "no symptoms" to "severe." The PGI$\mathrm{S}$-AD measure was collected in the daily diary along with the Itch NRS, Skin Pain NRS, and ADSS items; the other PROs (DLQI and POEM) were assessed during clinic visits. In addition, the clinician-completed EASI, an evaluation of disease extent and clinical signs, was used in the psychometric validation.

\section{Statistical analyses}

The following psychometric evaluation methods used in this study are in accordance with the published FDA guidance for assessing the measurement properties of PROs [6] and recent psychometric consensus discussions and presentations [12]. Unless otherwise stated, all analyses were conducted on eligible patients from the intent-to-treat (ITT) population who had weekly mean scores for the Itch NRS, Skin Pain NRS, or ADSS items at baseline. Analysis at visits following baseline includes all patients who had data at baseline and at the respective follow-up days or visits. All analyses were conducted using SAS Version 9.3 or higher (SAS Version 9. 2013. Cary, NC, SAS Institute Inc.).

\section{Test-retest reliability}

Test-retest reliability, which measures if instrument scores are reproducible across time, was assessed in a stable patient population during the interval between Week 0 and Week 1 as well as between Weeks 4 and 8 . Stable patients were defined as those in the ITT population with weekly mean PGI-S-AD scores between -0.50 and +0.50 during each time interval. Intra-class correlation coefficients (ICCs) were calculated between the initial and retest periods. An ICC of $\geq 0.70$ was considered acceptable agreement [13-15].

\section{Construct validity (convergent and divergent validity)}

Construct validity refers to the degree to which scores from one measure are theoretically consistent with those of another measure. Convergent and divergent validity were assessed using Spearman's correlations between each of the Itch NRS, Skin Pain NRS, and ADSS items, and the scores of the PGI-S-AD, DLQI, POEM, and EASI.
All analyses were conducted at Weeks 0 and 16. The strength of correlations was interpreted using Cohen's conventions, where $>0.70$ is large, $0.40-0.70$ is moderate, and $<0.40$ is small $[12-14,16,17]$.

It was hypothesized that convergent validity, evidenced by moderate or large correlations, would be demonstrated at Weeks 0 and 16 between each of the Itch NRS, Skin Pain NRS, and ADSS items with the other PROs related to AD symptoms (POEM, DLQI, and PGI-S-AD), and that divergent validity, evidenced by small-to-moderate correlations, would be demonstrated between each of the instruments of interest with the more distally related clinician-completed assessment (EASI).

\section{Known-groups validity (discriminant validity)}

Known-groups validity was assessed by exploring the ability of each instrument to discriminate between subgroups of patients with different underlying disease severity. Based on the evaluation of construct validity, measures correlating with the Itch NRS, Skin Pain NRS, or ADSS above the 0.35 criterion for acceptable correlations $[18,19]$ were considered in the analyses of knowngroups validity.

Patients were stratified into severity groups based on baseline scores of PGI-S-AD (weekly mean score of $<3$ "no symptoms to mild symptoms" and $\geq 3$ "moderateto-severe symptoms") and POEM (scores 0-7 "clear to mild," scores 8-16 "moderate-to-severe," and scores 17-28 "severe to very severe" [11]. The weekly average scores on the Itch NRS, Skin Pain NRS, and ADSS items were assessed between these groups using independent samples $t$-tests (2 groups) and analysis of covariance (ANCOVA) controlling for the effects of age, race, and gender ( $>2$ groups). When ANCOVA was used, post hoc $t$-tests assessed the mean weekly score between consecutive severity groups. Any severity group with $<20$ patients were omitted from the analysis to ensure sufficient data for interpretation.

\section{Responsiveness}

Responsiveness, the ability of the measure to detect change when change in the construct of relevance has occurred, was evaluated using ANCOVAs and post-hoc paired $t$-tests to assess significant differences in mean changes in the Itch NRS, Skin Pain NRS, and ADSS items from Week 0 to Week 4 and Week 0 to Week 16 between groups of patients with different degrees of change in the construct of relevance. The standardized response mean (SRM) [19] was used to interpret the magnitude of responsiveness of each measure; based on Cohen's recommendations [19], SRMs of 0.20, 0.50, and 0.80 represent small, moderate, and large changes, respectively [20]. 
Mean changes were assessed within 4 change categories of the POEM: (1) "much improved" patients who moved more than one health category to a better health category (>1 category improvement); (2) "improved" patients who moved by one health category to a better health category (1 category improvement); (3) "stable" patients who remained in the same health category (no category change); and (4) "declined" patients who moved to a worse health category ( $\geq 1$ category worsening). These categories were based on changes from baseline to the respective time point in the POEM severity category (scores 0-7 "clear to mild," scores 8-16 "moderate," and scores 17-28 "severe to very severe" [11]. It was hypothesized that statistically significant differences in the Itch NRS, Skin Pain NRS, and ADSS items would be observed between POEM change categories [11]. Differences in change scores between groups were tested using ANCOVA, controlling for age, gender, and race [21]. Post hoc $t$-tests and SRMs between consecutive change groups were also conducted.

\section{Meaningful change estimation}

Meaningful change refers to the individual-patient level of differences in scores in the domain of relevance which patients perceive as meaningful [6].

Anchor-based assessment An anchor-based analysis, with weekly mean PGI-S-AD serving as the anchor variable, was the primary method used to derive clinical interpretations of the Itch NRS, Skin Pain NRS, and ADSS items. Spearman's correlations were evaluated between the PGI-S-AD weekly average score and each measure at baseline, Week 4, and Week 16. Spearman's correlations were also used to compare the change in the PGI-S-AD weekly average with each measure's weekly average from baseline to Week 4 and Week 16.

To determine within patient meaningful change thresholds (MCTs), patients were classified into response groups based on their level of change in the PGIS-AD between baseline and Weeks 4 and 16. These groups included "very marked improvement" $(\leq-2.5$ weekly average score change), "marked improvement" $(>-2.5$ and $\leq-1.5)$, "minimal improvement" $(>-1.5$ and $\leq-0.5)$, "no change" ( $>-0.5$ and $<0.5)$, "minimal worsening" ( $\geq 0.5$ and $<1.5)$, and "marked worsening" ( $\geq 1.5)$. MCTs on the Itch NRS, Skin Pain NRS, and ADSS items were based on change from baseline to Week 16 (primary analysis) and baseline to Week 4 (sensitivity analysis) within PGI-S-AD severity groups. A range of MCT estimates (minimal, moderate, and large) were computed for changes in each measure based on observed changes in the minimal, marked, and very marked PGI-S-AD improvement groups. A final MCT estimate for each measure was taken as the MCT equivalent to a moderate degree of change.

Distribution-based methods Meaningful change analyses were also supported by distribution-based methods, which identify the raw score change on a measure that will produce a prespecified effect size and which identify a change which is beyond measurement error [22]. Distribution-based estimates were derived using weekly averages of the Itch NRS, Skin Pain NRS, and ADSS items at baseline. MCT estimates equivalent to $0.2,0.5$, and 0.8 pooled SDs were calculated. The Standard Error of Measurement (SEM) was calculated using the ICC from the test-retest analysis.

\section{Handling of missing data}

For Weeks 1, 2, 4, 8, and 12, weekly mean scores for Itch NRS, Skin Pain NRS, and ADSS items were set to missing if there were fewer than 4 non-missing values in the 7 -day period before the respective clinic visit. For Week 0 and Week 16 analyses, if there were fewer than 4 nonmissing assessments during the week prior to the visit, the 7-day window was extended by 1 day at a time (up to a maximum of 7 additional days) until there were at least 4 non-missing values.

\section{Results}

A total of 624 patients in AD1, 615 patients in AD2, and 440 patients in AD5 were included. Patients' baseline demographics and scores for the instruments of interest and other assessments are listed in Table 1.

\section{Test-retest reliability}

The results of the test-retest analysis for each instrument in each study are provided in Table 2. Across all studies, the ICCs ranged from 0.770 to 0.875 for the weekly average Itch NRS and from 0.753 to 0.845 for the weekly average Skin Pain NRS; this indicated acceptable agreement among stable patients using both 1-week and 4-week intervals. For ADSS Items 1, 2 and 3, the ICCs for the weekly average score ranged from 0.754 to $0.843,0.585$ to 0.921 , and 0.671 to 0.784 , respectively, indicating generally acceptable agreement using both 1 - and 4 -week assessment intervals. These high levels of agreement indicated that all measures had good test-retest validity.

\section{Construct validity (convergent and divergent validity)}

Results supporting convergent and divergent validity of the Itch NRS, Skin Pain NRS, and ADSS items are shown in Table 3. Moderate-to-large correlations between the reference $\mathrm{PRO}$ assessments of $\mathrm{AD}$ symptoms and the Itch NRS ( $r$ range: $0.483-0.762$ at baseline and $0.586-0.834$ at Week 16) and the Skin Pain NRS ( $r$ range: $0.474-0.727$ at 
Table 1 Descriptive analysis of baseline demographic characteristics for BREEZE-AD1, BREEZE-AD2, and BREEZE-AD5

\begin{tabular}{|c|c|c|c|}
\hline Characteristics & BREEZE-AD1 $(\mathrm{N}=624)$ & BREEZE-AD2 $(\mathrm{N}=615)$ & BREEZE-AD5 $(\mathrm{N}=440)$ \\
\hline Age, years & $35.6(12.81)$ & $34.7(12.77)$ & $39.5(16.06)$ \\
\hline \multicolumn{4}{|l|}{$\operatorname{Sex}, n(\%)$} \\
\hline Male & $391(62.7)$ & $381(62.0)$ & $224(50.9)$ \\
\hline Female & $233(37.3)$ & $234(38.0)$ & $216(49.1)$ \\
\hline \multicolumn{4}{|l|}{ Race, $n(\%)$} \\
\hline White & $366(58.9)$ & $421(68.5)$ & $251(57.3)$ \\
\hline African American & $2(0.3)$ & $0(0)$ & $80(18.3)$ \\
\hline Asian & $189(30.4)$ & $183(29.8)$ & $81(18.5)$ \\
\hline Other & $64(10.3)$ & $11(1.8)$ & $26(5.9)$ \\
\hline \multicolumn{4}{|l|}{ Alcohol use, $n(\%)$} \\
\hline Never & $214(34.3)$ & $220(35.8)$ & $103(23.4)$ \\
\hline Current & $381(61.1)$ & $353(57.4)$ & $291(66.1)$ \\
\hline Former & $29(4.6)$ & $42(6.8)$ & $46(10.5)$ \\
\hline \multicolumn{4}{|l|}{ Tobacco use, n (\%) } \\
\hline Never & $394(63.1)$ & $389(63.3)$ & $276(62.7)$ \\
\hline Current & $158(25.3)$ & $155(25.2)$ & $80(18.2)$ \\
\hline Former & $72(11.5)$ & $71(11.5)$ & $84(19.1)$ \\
\hline Duration since AD diagnosis, years & $25.7(15.10)$ & $24.2(13.86)$ & $23.6(16.65)$ \\
\hline Age at time of AD diagnosis, years & $10.2(14.54)$ & $10.8(14.22)$ & $15.9(20.30)$ \\
\hline IGA of $3, n(\%)$ & $363(58.2)$ & $305(49.7)$ & $256(58.2)$ \\
\hline IGA of $4, n(\%)$ & $261(41.8)$ & $309(50.3)$ & $184(41.8)$ \\
\hline EASI & $30.9(12.45)$ & $33.5(13.44)$ & $27.1(11.29)$ \\
\hline BSA & $51.0(22.34)$ & $53.5(22.62)$ & $40.9(22.73)$ \\
\hline Itch NRS & $6.5(2.09)$ & $6.6(2.17)$ & $7.2(2.17)$ \\
\hline Skin Pain NRS & $5.8(2.47)$ & $6.05(2.55)$ & $6.56(2.63)$ \\
\hline ADSS Item 2 & $3.0(4.67)$ & $1.8(2.31)$ & $2.3(2.89)$ \\
\hline DLQI & $13.6(7.27)$ & $14.4(8.09)$ & $14.7(7.28)$ \\
\hline PGI-S-AD & $3.9(0.82)$ & $3.9(0.85)$ & $4.0(0.85)$ \\
\hline POEM & $20.7(5.59)$ & $20.4(6.26)$ & $21.3(5.62)$ \\
\hline
\end{tabular}

Data are mean (standard deviation) unless stated otherwise

AD, atopic dermatitis; ADSS, Atopic Dermatitis Sleep Scale; BSA, body surface area; DLQI, Dermatology Life Quality Index; EASI, Eczema Area and Severity Index; IGA, Investigator's Global Assessment; N, number of total patients, NRS, numeric rating scale; PGI-S-AD, Patient Global Impression of Severity-Atopic Dermatitis; POEM, Patient Oriented Eczema Measure; PRO, patient-reported outcome

baseline and 0.549-0.768 at Week 16) supported convergent validity. Similarly, moderate correlations, supporting convergent validity, were generally observed between the PRO assessments and ADSS Item 1 ( $r$ range: 0.499-0.651 at baseline and $0.508-0.670$ at Week 16), Item 2 ( $r$ range: $0.368-0.468$ at baseline and 0.424 and 0.516 at Week 16$)$, and Item 3 ( $r$ range: $0.403-0.639$ at baseline and $0.466-$ 0.809 at Week 16).

Small-to-moderate correlations, supporting divergent validity, were observed between the clinical assessment and the following: Itch NRS ( $r$ range: $0.223-0.229$ at baseline and 0.398-0.505 at Week 16); Skin Pain NRS ( $r$ range: $0.222-0.251$ at baseline and $0.338-0.455$ at Week 16); ADSS Item 1 ( $r$ range $0.140-0.281$ at baseline and $0.363-0.403$ at Week 16$)$; ADSS Item 2 ( $r$ range:
$0.131-0.245$ at baseline and $0.254-0.357$ at Week 16), and; ADSS Item 3 ( $r$ range $0.152-0.298$ at baseline and 0.237 and 0.394 at Week 16 ).

\section{Known-groups validity}

Table 4 reports the findings of known-groups validity analysis of each instrument using PGI-S-AD and POEM subgroups to define $A D$ severity. At baseline, in all 3 studies, compared with patients in the moderate categories, patients in the severe categories of the PGI-S-AD and POEM had significantly more itching $(p<0.0001)$, skin pain $(p<0.0001)$, sleep disturbance $(p<0.0001)$, night-time awakenings $(p<0.01)$, and difficulty falling back asleep after waking $(p<0.0001)$ as demonstrated by higher mean scores on Itch NRS, Skin Pain NRS, ADSS 
Table 2 Test-retest reliability assessment of itch NRS, skin pain NRS and ADSS for BREEZE-AD1, BREEZE-AD2, and BREEZE-AD5

\begin{tabular}{|c|c|c|c|c|c|}
\hline \multirow[t]{2}{*}{ Measure } & \multirow[t]{2}{*}{ Study } & \multicolumn{2}{|c|}{ Baseline to Week 1} & \multicolumn{2}{|c|}{ Week 4 to Week 8} \\
\hline & & $N$ & $\mathrm{ICC}^{\mathrm{a}}(95 \% \mathrm{Cl})$ & $\mathbf{N}$ & $\mathrm{ICC}^{\mathrm{a}}(95 \% \mathrm{Cl})$ \\
\hline \multirow[t]{3}{*}{ Itch NRS } & BREEZE-AD1 & 620 & $0.863(0.842,0.882)$ & 599 & $0.783(0.750,0.812)$ \\
\hline & BREEZE-AD2 & 608 & $0.853(0.830,0.873)$ & 587 & $0.816(0.787,0.841)$ \\
\hline & BREEZE-AD5 & 432 & $0.875(0.851,0.896)$ & 405 & $0.770(0.727,0.807)$ \\
\hline \multirow[t]{3}{*}{ Skin pain NRS } & BREEZE-AD1 & 620 & $0.832(0.806,0.855)$ & 599 & $0.773(0.739,0.804)$ \\
\hline & BREEZE-AD2 & 608 & $0.845(0.821,0.866)$ & 587 & $0.808(0.778,0.834)$ \\
\hline & BREEZE-AD5 & 432 & $0.832(0.801,0.859)$ & 405 & $0.753(0.708,0.792)$ \\
\hline \multirow[t]{3}{*}{ ADSS item 1} & BREEZE-AD1 & 620 & $0.839(0.814,0.861)$ & 599 & $0.754(0.717,0.786)$ \\
\hline & BREEZE-AD2 & 607 & $0.843(0.819,0.865)$ & 587 & $0.776(0.742,0.806)$ \\
\hline & BREEZE-AD5 & 432 & $0.834(0.803,0.861)$ & 405 & $0.792(0.753,0.826)$ \\
\hline \multirow[t]{3}{*}{ ADSS item 2} & BREEZE-AD1 & 620 & $0.921(0.908,0.932)$ & 599 & $0.903(0.887,0.917)$ \\
\hline & BREEZE-AD2 & 607 & $0.765(0.730,0.796)$ & 587 & $0.585(0.529,0.635)$ \\
\hline & BREEZE-AD5 & 432 & $0.921(0.906,0.934)$ & 405 & $0.918(0.901,0.932)$ \\
\hline \multirow[t]{3}{*}{ ADSS item 3} & BREEZE-AD1 & 512 & $0.780(0.743,0.811)$ & 353 & $0.703(0.646,0.752)$ \\
\hline & BREEZE-AD2 & 497 & $0.761(0.722,0.796)$ & 315 & $0.682(0.618,0.737)$ \\
\hline & BREEZE-AD5 & 369 & $0.784(0.741,0.820)$ & 239 & $0.671(0.596,0.735)$ \\
\hline
\end{tabular}

ADSS, Atopic Dermatitis Sleep Scale; Cl, confidence interval; ICC, intra-class correlation coefficient; N, number of total patients, NRS, numeric rating scale

${ }^{\text {a }} \mathrm{An}$ ICC of 0.70 and above is considered acceptable agreement

Items 1, 2, and 3, respectively. These findings suggest that the Itch NRS, Skin Pain NRS, and ADSS items are able to distinguish between known groups based on disease severity.

\section{Responsiveness}

The responsiveness of the Itch NRS, Skin Pain NRS, and ADSS items between Weeks 0 and 16 and between Weeks 0 and 4 are shown in Tables 5 and 6 , respectively. In all three studies, the magnitude of improvement in each instrument increased with greater improvement in the POEM, supporting the ability of each measure to detect change in the construct of relevance where change has occurred. For the Itch NRS and Skin Pain NRS, in each study at Weeks 4 and 16, the "much improved" group statistically significantly differed from the "improved" group ( $p<0.001$ for Itch NRS, $p<0.05$ for Skin Pain NRS), and the "improved" category statistically significantly differed from the "stable" group ( $p<0.0001$ for both). In each study, at Week 16, the scores of each ADSS item increased with each improvement category; however, not all comparisons between consecutive improvement categories were statistically significant (Table 5).

\section{Meaningful change estimation Anchor-based}

Anchor-based estimates of the MCTs (minimal, moderate, and large) for each measure are listed in Table 7. For the 0-10 Itch NRS, the final estimate of meaningful change was -4.0 , with a reduction of 4 categories on the instrument consistent with moderate degree of change. Similarly, the final MCT for the 0-10 Skin Pain NRS was taken as -4.0 , also equivalent to a moderate degree of change. The final MCTs for ADSS Items 1, 2, and 3, respectively were $-1.25,-1.50$, and -1.25 , indicating that the smallest weekly averages are consistent with at least a moderate degree of improvement.

\section{Distribution-based}

Distribution-based MCTs are listed in Table 8. Compared with anchor-based thresholds, SD and SEM estimates were smaller for all measures but the ADSS Item 2; this indicated that the anchor-based estimates are generally above measurement error and thus that improvements in these measures reflect a true improvement in condition severity. The larger distribution-based estimates for ADSS Item 2 reflected the large variability and skewness of this measure at baseline.

\section{Discussion}

This study evaluated the psychometric properties of the Itch NRS, Skin Pain NRS, and ADSS using data from three clinical trials of patients with moderate-to-severe AD. For each measure, assessment of test-retest reliability found high levels of agreement in stable groups of patients across all three studies for both 1-week and 4-week comparisons, indicating reliability of each instrument when no change would be expected. As hypothesized, the construct validity of each measure was also demonstrated, with moderate-to-large correlations with 
Table 3 Correlations between the Itch NRS, skin pain NRS, and ADSS with other instruments for BREEZE-AD1, BREEZE-AD2, and BREEZE-AD5 at baseline and week 16

\begin{tabular}{|c|c|c|c|c|c|c|c|}
\hline \multirow[t]{2}{*}{ Measure } & \multirow[t]{2}{*}{ Correlation } & \multicolumn{2}{|c|}{ BREEZE-AD $1^{\text {a }}$ correlation } & \multicolumn{2}{|c|}{ BREEZE-AD2 ${ }^{\mathrm{a}}$ correlation } & \multicolumn{2}{|c|}{ BREEZE-AD5 ${ }^{\text {a }}$ correlation } \\
\hline & & Baseline & Week 16 & Baseline & Week 16 & Baseline & Week 16 \\
\hline \multirow[t]{6}{*}{ Itch NRS } & ClinRO & & & & & & \\
\hline & EASI & 0.229 & 0.398 & 0.223 & 0.505 & 0.225 & 0.498 \\
\hline & $P R O$ & & & & & & \\
\hline & PGI-S-AD & 0.762 & 0.767 & 0.759 & 0.788 & 0.752 & 0.834 \\
\hline & DLQI & 0.495 & 0.590 & 0.506 & 0.586 & 0.544 & 0.666 \\
\hline & POEM & 0.483 & 0.607 & 0.586 & 0.640 & 0.505 & 0.667 \\
\hline \multirow[t]{6}{*}{ Skin pain NRS } & ClinRO & & & & & & \\
\hline & EASI & 0.222 & 0.338 & 0.225 & 0.455 & 0.251 & 0.444 \\
\hline & $P R O$ & & & & & & \\
\hline & PGI-S-AD & 0.707 & 0.691 & 0.727 & 0.710 & 0.689 & 0.768 \\
\hline & DLQ। & 0.529 & 0.549 & 0.591 & 0.582 & 0.586 & 0.658 \\
\hline & POEM & 0.474 & 0.575 & 0.634 & 0.621 & 0.536 & 0.657 \\
\hline \multirow[t]{6}{*}{ ADSS item 1} & ClinRO & & & & & & \\
\hline & EASI & 0.281 & 0.363 & 0.140 & 0.403 & 0.233 & 0.376 \\
\hline & $P R O$ & & & & & & \\
\hline & PGI-S-AD & 0.651 & 0.582 & 0.624 & 0.597 & 0.627 & 0.670 \\
\hline & DLQI & 0.570 & 0.576 & 0.598 & 0.554 & 0.522 & 0.608 \\
\hline & POEM & 0.507 & 0.508 & 0.531 & 0.518 & 0.499 & 0.582 \\
\hline \multirow[t]{6}{*}{ ADSS item 2} & ClinRO & & & & & & \\
\hline & EASI & 0.245 & 0.254 & 0.131 & 0.357 & 0.223 & 0.350 \\
\hline & PRO & & & & & & \\
\hline & PGI-S-AD & 0.451 & 0.424 & 0.435 & 0.446 & 0.449 & 0.495 \\
\hline & DLQI & 0.445 & 0.486 & 0.447 & 0.486 & 0.411 & 0.516 \\
\hline & POEM & 0.368 & 0.436 & 0.468 & 0.489 & 0.422 & 0.473 \\
\hline \multirow[t]{6}{*}{ ADSS item 3} & ClinRO & & & & & & \\
\hline & EASI & 0.298 & 0.237 & 0.152 & 0.394 & 0.187 & 0.300 \\
\hline & $P R O$ & & & & & & \\
\hline & PGI-S-AD & 0.555 & 0.636 & 0.603 & 0.641 & 0.639 & 0.809 \\
\hline & DLQI & 0.516 & 0.466 & 0.526 & 0.505 & 0.516 & 0.581 \\
\hline & POEM & 0.439 & 0.472 & 0.460 & 0.474 & 0.403 & 0.563 \\
\hline
\end{tabular}

ADSS, Atopic Dermatitis Sleep Scale; ClinRO, clinician-reported outcome; DLQI, Dermatology Quality of Life Index; EASI, Eczema Area and Severity Index; NRS, Numeric Rating Scale; PGI-S-AD, Patient Global Impression of Severity-Atopic Dermatitis; POEM, Patient Oriented Eczema Measure; PRO, patient-reported outcome

a Spearman's correlation coefficients were calculated as correlations between assessments and continuous reference measures. Concurrent validity was small if the resulting coefficient was $<0.4$, moderate if the coefficient was $>0.4-0.7$, and large if the coefficient was $>0.7$

other PROs (POEM, DLQI, and PGI-S-AD) supporting convergent validity and smaller correlations with the more distally-related provider assessment (EASI) supporting divergent validity. These findings suggest that the Itch NRS, Skin Pain NRS and ADSS measure the underlying concept of AD symptomatology and, moreover, encapsulate unique information regarding disease symptoms, which can complement clinician-reported assessments in clinical trials. In addition, comparisons of the Itch NRS, Skin Pain NRS, and each ADSS item between PGI-S-AD and POEM severity categories demonstrated each measure's ability to distinguish between known groups based on disease severity. Responsiveness was established through the ability of each instrument to discriminate significantly between subgroups of patients based on four change categories of the POEM ("much improved," "improved," "stable" and "declined"). Overall, the Itch NRS, Skin Pain NRS, and ADSS were determined to be highly reliable, valid, and responsive, supporting the use of these PRO instruments in daily assessment of $\mathrm{AD}$ symptoms in adults with moderate-to-severe AD.

Using anchor- and distribution-based analyses, thresholds for interpreting change of each measure were derived as criteria to assess treatment benefits in patients 
Table 4 Known-groups validity of the itch NRS, skin pain NRS, and ADSS using PGI-S-AD and POEM subgroups at baseline for BREEZE-AD1, BREEZE-AD2, and BREEZE-AD5

\begin{tabular}{|c|c|c|c|c|c|c|}
\hline \multirow[t]{2}{*}{ Measure } & & \multicolumn{2}{|c|}{ PGI-S-AD category } & \multicolumn{3}{|l|}{ POEM category } \\
\hline & & $\begin{array}{l}\leq 3 \text { (no to mild } \\
\text { symptoms) }\end{array}$ & $\begin{array}{l}>3 \text { (moderate to } \\
\text { severe symptoms) }\end{array}$ & 0-7 (clear to mild) & $\begin{array}{l}8-16 \\
\text { (moderate to } \\
\text { severe) }\end{array}$ & $\begin{array}{l}17-28 \text { (severe } \\
\text { to very severe) }\end{array}$ \\
\hline \multirow[t]{12}{*}{ Itch NRS } & BREEZE-AD1 & & & & & \\
\hline & Sample size & 118 & 497 & 13 & 125 & 470 \\
\hline & LSM (SE) at baseline & $4.22(0.296)$ & $7.43(0.254)$ & $N / A^{b}$ & $5.35(0.322)$ & $7.46(0.283)$ \\
\hline & Between-group comparisons ${ }^{\mathrm{a}}$ & - & $<0.0001$ & - & $N / A^{b}$ & $<0.0001$ \\
\hline & BREEZE-AD2 & & & & & \\
\hline & Sample size & 110 & 490 & 26 & 126 & 445 \\
\hline & LSM (SE) at baseline & $3.58(0.502)$ & $6.79(0.471)$ & $3.05(0.628)$ & $5.09(0.537)$ & $6.89(0.510)$ \\
\hline & Between-group comparisons ${ }^{a}$ & - & $<0.0001$ & - & $<0.0001$ & $<0.0001$ \\
\hline & BREEZE-AD5 & & & & & \\
\hline & Sample size & 61 & 364 & 9 & 72 & 342 \\
\hline & LSM (SE) at baseline & $3.95(0.328)$ & $7.59(0.260)$ & $N / A^{b}$ & $4.89(0.362)$ & $7.29(0.286)$ \\
\hline & Between-group comparisons ${ }^{a}$ & - & $<0.0001$ & - & $N / A^{b}$ & $<0.0001$ \\
\hline \multirow[t]{12}{*}{ Skin pain NRS } & BREEZE-AD1 & & & & & \\
\hline & Sample Size & 118 & 497 & 13 & 125 & 470 \\
\hline & LSM (SE) at baseline & $3.36(0.372)$ & $6.73(0.319)$ & $N / A^{b}$ & $4.58(0.394)$ & $6.75(0.346)$ \\
\hline & Between-group comparisons ${ }^{\mathrm{a}}$ & - & $<0.0001$ & - & $N / A^{b}$ & $<0.0001$ \\
\hline & BREEZE-AD2 & & & & & \\
\hline & Sample size & 110 & 490 & 26 & 126 & 445 \\
\hline & LSM (SE) at baseline & $2.94(0.617)$ & $6.29(0.580)$ & $1.96(0.723)$ & $4.09(0.619)$ & $6.47(0.587)$ \\
\hline & Between-group comparisons ${ }^{\mathrm{a}}$ & - & $<0.0001$ & - & $<0.0001$ & $<0.0001$ \\
\hline & BREEZE-AD5 & & & & & \\
\hline & Sample size & 61 & 364 & 9 & 72 & 342 \\
\hline & LSM (SE) at baseline & $3.55(0.436)$ & $7.07(0.345)$ & $N / A^{b}$ & $4.05(0.446)$ & $6.83(0.353)$ \\
\hline & Between-group comparisons ${ }^{\mathrm{a}}$ & - & $<0.0001$ & - & $N / A^{b}$ & $<0.0001$ \\
\hline \multirow[t]{12}{*}{ ADSS item 1} & BREEZE-AD1 & & & & & \\
\hline & Sample size & 118 & 497 & 13 & 125 & 470 \\
\hline & LSM (SE) at baseline & $1.04(0.167)$ & $2.36(0.143)$ & $N / A^{b}$ & $1.45(0.174)$ & $2.38(0.152)$ \\
\hline & Between-group comparisons ${ }^{\mathrm{a}}$ & - & $<0.0001$ & - & $N / A^{b}$ & $<0.0001$ \\
\hline & BREEZE-AD2 & & & & & \\
\hline & Sample size & 110 & 490 & 26 & 126 & 445 \\
\hline & LSM (SE) at baseline & $1.06(0.286)$ & $2.29(0.269)$ & $0.94(0.341)$ & $1.53(0.292)$ & $2.34(0.277)$ \\
\hline & Between-group comparisons ${ }^{\mathrm{a}}$ & - & $<0.0001$ & - & 0.0089 & $<0.0001$ \\
\hline & BREEZE-AD5 & & & & & \\
\hline & Sample size & 61 & 364 & 9 & 72 & 342 \\
\hline & LSM (SE) at baseline & $1.04(0.201)$ & $2.54(0.159)$ & $N / A^{b}$ & $1.38(0.209)$ & $2.43(0.165)$ \\
\hline & Between-group comparisons ${ }^{a}$ & - & $<0.0001$ & - & $N / A^{b}$ & $<0.0001$ \\
\hline
\end{tabular}


Table 4 (continued)

\begin{tabular}{|c|c|c|c|c|c|c|}
\hline \multirow[t]{2}{*}{ Measure } & & \multicolumn{2}{|c|}{ PGI-S-AD category } & \multicolumn{3}{|l|}{ POEM category } \\
\hline & & $\begin{array}{l}\leq 3 \text { (no to mild } \\
\text { symptoms) }\end{array}$ & $\begin{array}{l}>3 \text { (moderate to } \\
\text { severe symptoms) }\end{array}$ & $0-7$ (clear to mild) & $\begin{array}{l}8-16 \\
\text { (moderate to } \\
\text { severe) }\end{array}$ & $\begin{array}{l}17-28 \text { (severe } \\
\text { to very severe) }\end{array}$ \\
\hline \multirow[t]{12}{*}{ ADSS item 2} & BREEZE-AD1 & & & & & \\
\hline & Sample size & 118 & 497 & 13 & 125 & 470 \\
\hline & LSM (SE) at baseline & $1.18(0.809)$ & $3.22(0.694)$ & $\mathrm{N} / \mathrm{A} \wedge \mathrm{b}$ & $1.36(0.805)$ & $3.35(0.706)$ \\
\hline & Between-group comparisons ${ }^{a}$ & - & $<0.0001$ & - & $N / A^{b}$ & 0.0001 \\
\hline & BREEZE-AD2 & & & & & \\
\hline & Sample size & 110 & 490 & 26 & 126 & 445 \\
\hline & LSM (SE) at baseline & $1.00(0.622)$ & $2.11(0.585)$ & $0.91(0.727)$ & $1.46(0.622)$ & $2.15(0.590)$ \\
\hline & Between-group comparisons ${ }^{a}$ & - & $<0.0001$ & - & 0.2514 & 0.0024 \\
\hline & BREEZE-AD5 & & & & & \\
\hline & Sample Size & 61 & 364 & 9 & 72 & 342 \\
\hline & LSM (SE) at baseline & $1.12(0.525)$ & $2.87(0.416)$ & $N / A^{b}$ & $1.32(0.529)$ & $2.79(0.418)$ \\
\hline & Between-group comparisons ${ }^{a}$ & - & $<0.0001$ & - & $N / A^{b}$ & 0.0001 \\
\hline \multirow[t]{11}{*}{ ADSS item 3} & BREEZE-AD1 & & & & & \\
\hline & Sample Size & 63 & 442 & 10 & 74 & 415 \\
\hline & LSM (SE) at baseline & $1.42(0.175)$ & $2.46(0.136)$ & $N / A^{b}$ & $1.74(0.172)$ & $2.50(0.139$ \\
\hline & $\begin{array}{l}\text { Between-group comparisons }{ }^{\text {a }} \\
\text { BREEZE-AD2 }\end{array}$ & - & $<0.0001$ & - & $N / A^{b}$ & $<0.0001$ \\
\hline & Sample size & 60 & 423 & 11 & 84 & 385 \\
\hline & LSM (SE) at baseline & $1.30(0.267)$ & $2.35(0.240)$ & $N / A^{b}$ & $1.63(0.266)$ & $2.38(0.247)$ \\
\hline & Between-group comparisons ${ }^{a}$ & - & $<0.0001$ & - & $N / A^{b}$ & $<0.0001$ \\
\hline & BREEZE-AD5 & & & & & \\
\hline & Sample size & 38 & 324 & 4 & 48 & 309 \\
\hline & LSM (SE) at baseline & $1.53(0.190)$ & $2.82(0.137)$ & $N / A^{b}$ & $2.02(0.195)$ & $2.72(0.143)$ \\
\hline & Between-group comparisons ${ }^{a}$ & - & $<0.0001$ & - & $N / A^{b}$ & $<0.0001$ \\
\hline
\end{tabular}

ADSS, Atopic Dermatitis Sleep Scale, NRS, Numeric Rating Scale, PGI-S-AD, Patient Global Impression of Severity-Atopic Dermatitis, POEM0, Patient Oriented Eczema Measure; SD, standard deviation

${ }^{a}$ Between-group comparisons. The LS mean and SE are derived from an ANCOVA adjusting for age, sex, and race. The $p$ value for the pairwise comparisons between consecutive severity groups is assessing differences in scores between groups

${ }^{b}$ Where numbers were $<20$ in any severity group, this severity group was omitted from the analysis and the analysis was conducted on the remaining severity groups

with AD. Four-point changes in the Itch NRS and Skin Pain NRS were found to demonstrate clinically meaningful responses in itch and skin pain severity, respectively. This 4-point change in the Itch NRS is consistent with minimal clinically important differences reported for similar itch scales [23, 24]. Changes of 1.25 points in ADSS Items 1 and 3 and 1.5 points in ADSS Item 2 were found to optimally demonstrate clinically meaningful improvements in sleep disturbance. These findings further confirm previous psychometric validation data of itch NRS in AD and psoriasis [23, 24].

The potential importance of these measures in clinical practice is indicated by the fact that patients with
AD have identified itch, skin pain, and sleep disturbance as bothersome and distressing symptoms of their disease [25], but these are difficult or impossible for clinicians to assess using conventional tools. There is thus an unmet need for measures which can assess these patient-perceived symptoms. For example, EASI or BSA instruments assess important signs of disease, but these do not capture the impacts of itch, skin pain and sleep disturbance from $\mathrm{AD}$ as perceived by patients. Existing PROs of AD, such as the POEM, and Scoring Atopic Dermatitis or SCORAD include sleep items, but these items are included as part of a total score and do not assess the full impact of itch on sleep disturbance [11, 
Table 5 Within group mean and median change scores for responsiveness of the itch NRS, skin pain NRS, and ADSS to change on the POEM between baseline and week 16 for BREEZE-AD1, BREEZE-AD2, and BREEZE-AD5

\section{POEM groups at week 16}

Much improved (>1 category Improved (1 category

improvement)
Stable (No category change)
Declined

$(\geq 1$ category worsening)

\section{Itch NRS}

BREEZE-AD1

Sample Size

Mean (SD) change

Median change

Between-group comparisons ${ }^{\mathrm{a}}$

$-$

BREEZE-AD2

Sample size

Mean (SD) at baseline

Median change

Between-group comparisons ${ }^{\mathrm{a}}$

BREEZE-AD5

Sample size

Mean (SD) at baseline

Median change

Between-group comparisons ${ }^{a}$

\section{Skin pain NRS}

BREEZE-AD1

Sample size

Mean (SD) change

Median change

Between-group comparisons ${ }^{\mathrm{a}}$

BREEZE-AD2

Sample size

Mean (SD) at baseline

Median change

Between-group comparisons ${ }^{a}$

BREEZE-AD5

Sample size

Mean (SD) at baseline

Median change

Between-group comparisons ${ }^{\mathrm{a}}$

\section{ADSS item 1}

BREEZE-AD1

Sample size

Mean (SD) change

Median change

Between-group comparisons ${ }^{\mathrm{a}}$

BREEZE-AD2

Sample size

Mean (SD) at baseline

Median change

Between-group comparisons ${ }^{a}$

BREEZE-AD5

Sample size

Mean (SD) at baseline
71

$-4.64(2.333)$

$-4.86$

85

$-4.49(2.162)$

$-4.5$

198

$-3.03(2.025)$

$-3.14$

$<0.0001$

163

-3.01 (2.183)

$-2.86$

$<0.0001$

104

$-3.59(2.245)$

$-3.54$

$<0.0001$

198

$-2.82(2.289)$

$-2.79$

$<0.0001$

163

$-3.17(2.309)$

$-2.74$

$<0.0001$

49

$-4.80(2.842)$

$-4.86$

71

$-1.40(1.045)$

$-1.17$

$-0.98(0.904)$

$-0.91$

0.0022

163

$-1.12(0.951)$

$-1.00$

0.0144

104

$-1.69(1.245)$

$-3.60(2.398)$

-1.45 (0.924)

$-1.30(0.956)$
263

$-1.42(1.986)$

25

$-1.14$

$0.10(1.964)$

$-0.12$

$<0.0001$

0.0007

263

-1.47 (2.166)

$-1.29$

$0.13(2.602)$

0.07

$<0.0001$

0.0042

176

$-1.46(2.109)$

8

$-1.31$

-0.01 (3.105)

$-0.21$

$<0.0001$

0.1167

263

25

-1.34 (2.220)

$0.53(2.236)$

$-1.00$

0.00

$<0.0001$

0.0002

263

23

$-1.36(2.395)$

0.04 (2.594)

$-1.29$

0.25

$<0.0001$

0.0203

176

$-1.48(2.354)$

$-1.21$

$0.21(4.211)$

$-1.21$

$-0.38$

0.0932

263

$-0.51(0.977)$

25

$-0.29$

$0.34(1.011)$

$<0.0001$

$<0.0001$

263

23

-0.38 (0.937)

0.10 (0.739)

$-0.29$

0.00

$<0.0001$

0.0453
176

$-0.34(0.842)$
8
$-0.06(0.973)$ 
Table 5 (continued)

\begin{tabular}{|c|c|c|c|c|}
\hline & \multicolumn{4}{|l|}{ POEM groups at week 16} \\
\hline & $\begin{array}{l}\text { Much improved ( }>1 \text { category } \\
\text { improvement) }\end{array}$ & $\begin{array}{l}\text { Improved (1 category } \\
\text { improvement) }\end{array}$ & $\begin{array}{l}\text { Stable (No category } \\
\text { change) }\end{array}$ & $\begin{array}{l}\text { Declined } \\
\text { ( } \geq 1 \text { category } \\
\text { worsening) }\end{array}$ \\
\hline Median change & -1.71 & -1.07 & -0.14 & 0.00 \\
\hline Between-group comparisons ${ }^{\mathrm{a}}$ & - & 0.0386 & $<0.0001$ & 0.5370 \\
\hline \multicolumn{5}{|l|}{ ADSS item 2} \\
\hline \multicolumn{5}{|l|}{ BREEZE-AD 1} \\
\hline Sample size & 71 & 198 & 263 & 25 \\
\hline Mean (SD) change & $-2.47(4.141)$ & $-1.60(2.491)$ & $-1.05(2.954)$ & $-0.04(1.483)$ \\
\hline Median change & -1.14 & -1.00 & -0.57 & 0.00 \\
\hline Between-group comparisons ${ }^{a}$ & - & 0.0431 & 0.0695 & 0.0957 \\
\hline \multicolumn{5}{|l|}{ BREEZE-AD2 } \\
\hline Sample size & 85 & 163 & 263 & 23 \\
\hline Mean (SD) at baseline & $-1.63(1.604)$ & $-1.36(2.434)$ & $-0.70(1.655)$ & $-0.43(1.183)$ \\
\hline Median change & -1.14 & -0.86 & -0.45 & -0.29 \\
\hline Between-group comparisons ${ }^{\mathrm{a}}$ & - & 0.2260 & 0.0004 & 0.6256 \\
\hline \multicolumn{5}{|l|}{ BREEZE-AD5 } \\
\hline Sample size & 49 & 104 & 176 & 8 \\
\hline Mean (SD) at baseline & $-2.16(1.665)$ & $-1.55(2.631)$ & $-0.51(1.526)$ & $0.24(0.592)$ \\
\hline Median change & -1.86 & -0.86 & -0.43 & 0.00 \\
\hline Between-group comparisons ${ }^{\mathrm{a}}$ & - & 0.0753 & 0.0001 & 0.2183 \\
\hline \multicolumn{5}{|l|}{ ADSS item 3} \\
\hline \multicolumn{5}{|l|}{ BREEZE-AD 1} \\
\hline Sample size & 22 & 71 & 162 & 10 \\
\hline Mean (SD) change & $-1.00(0.916)$ & $-0.77(0.981)$ & $-0.32(0.868)$ & $0.70(1.023)$ \\
\hline Median change & -0.98 & -0.71 & -0.23 & 0.65 \\
\hline Between-group comparisons ${ }^{\mathrm{a}}$ & - & 0.2873 & 0.0011 & 0.0005 \\
\hline \multicolumn{5}{|l|}{ BREEZE-AD2 } \\
\hline Sample size & 9 & 51 & 141 & 10 \\
\hline Mean (SD) at baseline & $-1.11(0.906)$ & $-0.76(0.869)$ & $-0.22(0.940)$ & $0.43(0.838)$ \\
\hline Median change & -1.25 & -0.80 & -0.17 & 0.50 \\
\hline Between-group comparisons ${ }^{\mathrm{a}}$ & - & 0.3592 & 0.0003 & 0.0574 \\
\hline \multicolumn{5}{|l|}{ BREEZE-AD5 } \\
\hline Sample size & 15 & 52 & 115 & 2 \\
\hline Mean (SD) at baseline & $-1.60(0.951)$ & $-1.27(1.021)$ & $-0.18(0.794)$ & $-0.79(1.111)$ \\
\hline Median change & -1.86 & -1.14 & 0.00 & -0.79 \\
\hline Between-group comparisons ${ }^{\mathrm{a}}$ & - & 0.4839 & $<0.0001$ & 0.2654 \\
\hline
\end{tabular}

ADSS, Atopic Dermatitis Sleep Scale, ANOVA, analysis of variance; NRS, Numeric Rating Scale; POEM, Patient Oriented Eczema Measure; SD, standard deviation

${ }^{\text {a }}$ Between-group comparisons. The $p$ value for the pairwise comparisons between consecutive severity groups was derived from an ANOVA assessing differences in score change between groups

26]. These existing instruments are thus limited in their ability to accurately evaluate the impact of treatments on specific patient-reported symptoms in clinical trials. The implementation of the Itch NRS, Skin Pain NRS, and ADSS in AD clinical trials may therefore address this unmet need. Further, given the increasing use of electronic diaries in clinical settings, these low burden, simple, and specific PRO measures of symptoms may be useful in guiding treatment decisions in practice.

Though this study demonstrated strong evidence for the reliability, validity, and responsiveness of the Itch NRS, Skin Pain NRS, and ADSS, the data used in this psychometric validation are from a clinical trial and hence may not be generalizable to clinical practice. In addition, the inclusion and exclusion criteria of the three 
Table 6 Within group mean and median change scores for responsiveness of the itch NRS, skin pain NRS, and ADSS to change on the POEM between baseline and week 4 for BREEZE-AD1, BREEZE-AD2, and BREEZE-AD5

POEM groups at week 4

Much Improved (> 1 Category Improved (1 Category

Improvement)

Improvement)
Stable (No Category Change)
Declined $(\geq 1$

Category

Worsening)

\section{Itch NRS}

BREEZE-AD1

Samplesize

Mean (SD) change

63

$-3.85(1.943)$

Median change

$-3.67$

Between-group comparisons ${ }^{\mathrm{a}}$

BREEZE-AD2

Sample size

Mean (SD) at baseline

Median change

Between-group comparisons ${ }^{\mathrm{a}}$

\section{BREEZE-AD5}

Sample size

Mean (SD) at baseline

Median change

Between-group comparisons ${ }^{\mathrm{a}}$

\section{Skin pain NRS}

BREEZE-AD1

Sample size

Mean (SD) change

Median change

Between-group comparisons ${ }^{\mathrm{a}}$

BREEZE-AD2

Sample size

Mean (SD) at baseline

Median change

Between-group comparisons ${ }^{a}$

BREEZE-AD5

Sample size

Mean (SD) at baseline

Median change

Between-group comparisons ${ }^{\mathrm{a}}$

\section{ADSS item 1}

BREEZE-AD1

Sample size

Mean (SD) change

Median change

Between-group comparisons ${ }^{\mathrm{a}}$

BREEZE-AD2

Sample size

Mean (SD) at baseline

Median change

Between-group comparisons ${ }^{a}$

BREEZE-AD5

Sample size

Mean (SD) at baseline
69

$-3.90(2.318)$

$-3.71$

$-$

35

$-4.12(2.261)$

$-3.71$

$-$

63

$-3.49(2.111)$

$-3.14$

$-$

69

$-4.13(2.412)$

$-4.00$

35

$-4.24(2.361)$

$-4.00$

63

$-1.31(0.958)$

$-1.29$

$-$

69

$-1.30(0.886)$

$-1.14$

$-$

35

$-1.49(0.918)$
191

$-2.29(1.779)$

$-2.14$

$<0.0001$

190

$-2.45(2.101)$

$-2.29$

$<0.0001$

114

$-2.56(2.059)$

$-2.30$

0.0002

191

$-2.24(1.970)$

$-1.86$

$<0.0001$

190

$-2.66(2.290)$

$-2.29$

$<0.0001$

114

-2.49 (2.119)

$-2.15$

$<0.0001$

191

$-0.75(0.828)$

$-0.71$

$<0.0001$

190

$-0.85(0.894)$

$-0.71$

0.0001

114

$-0.88(0.839)$
301

-1.07 (1.629)

$-0.86$

$<0.0001$

$0.21(1.942)$

0.64

0.0002

286

$-1.08(1.634)$

$-0.86$

$<0.0001$

23

$.14(1.049)$

0.17

0.0030

217

13

$-1.15(1.627)$

$-0.81(1.569)$

$-0.86$

$-0.57$

$<0.0001$

0.9320

301

$-0.97(1.773)$

26

$-0.71$

$0.31(1.726)$

$<0.0001$

0.0007

286

$-0.97(1.826)$

$-0.86$

$<0.0001$

$0.20(1.206)$

0.43

0.0118

217

$-1.19(1.889)$

13

$-0.90$

$-0.38(1.667)$

$<0.0001$

$-0.57$

0.3379

301

$-0.42(0.813)$

26

$-0.29$

$0.31(1.061)$

0.00

$<0.0001$

$<0.0001$

23

-0.35 (0.823)

$0.20(0.507)$

$-0.31$

0.14

$<0.0001$

0.0062

217

13

$-0.46(0.814)$
$-0.12(0.787)$ 
Table 6 (continued)

\begin{tabular}{|c|c|c|c|c|}
\hline & \multicolumn{4}{|l|}{ POEM groups at week 4} \\
\hline & $\begin{array}{l}\text { Much Improved (> } 1 \text { Category } \\
\text { Improvement) }\end{array}$ & $\begin{array}{l}\text { Improved (1 Category } \\
\text { Improvement) }\end{array}$ & $\begin{array}{l}\text { Stable (No Category } \\
\text { Change) }\end{array}$ & $\begin{array}{l}\text { Declined ( } \geq 1 \\
\text { Category } \\
\text { Worsening) }\end{array}$ \\
\hline Median change & -1.43 & -0.88 & -0.29 & 0.00 \\
\hline Between-group comparisons ${ }^{\mathrm{a}}$ & - & 0.0014 & $<0.0001$ & 0.2903 \\
\hline \multicolumn{5}{|l|}{ ADSS item 2} \\
\hline \multicolumn{5}{|l|}{ BREEZE-AD1 } \\
\hline Sample size & 63 & 191 & 301 & 26 \\
\hline Mean (SD) change & $-1.85(2.836)$ & $-1.45(3.027)$ & $-0.70(2.119)$ & $0.35(2.133)$ \\
\hline Median change & -1.00 & -0.71 & -0.43 & 0.15 \\
\hline Between-group comparisons ${ }^{\mathrm{a}}$ & - & 0.2945 & 0.0019 & 0.0375 \\
\hline \multicolumn{5}{|l|}{ BREEZE-AD2 } \\
\hline Sample size & 69 & 190 & 286 & 23 \\
\hline Mean (SD) at baseline & $-1.34(1.490)$ & $-1.12(2.629)$ & $-0.52(2.105)$ & $0.12(0.601)$ \\
\hline Median change & -0.86 & -0.56 & -0.43 & 0.00 \\
\hline Between-group comparisons ${ }^{\mathrm{a}}$ & - & 0.3931 & 0.0096 & 0.1092 \\
\hline \multicolumn{5}{|l|}{ BREEZE-AD5 } \\
\hline Sample size & 35 & 114 & 217 & 13 \\
\hline Mean (SD) at baseline & $-1.66(1.522)$ & $-1.13(1.365)$ & $-0.54(1.208)$ & $0.06(0.791)$ \\
\hline Median change & -1.29 & -0.67 & -0.31 & 0.29 \\
\hline Between-group comparisons ${ }^{\mathrm{a}}$ & - & 0.1450 & 0.0001 & 0.1491 \\
\hline \multicolumn{5}{|l|}{ ADSS item 3} \\
\hline \multicolumn{5}{|l|}{ BREEZE-AD1 } \\
\hline Sample size & 20 & 80 & 201 & 9 \\
\hline Mean (SD) change & $-1.15(1.024)$ & $-0.73(0.833)$ & $-0.31(0.807)$ & $0.27(0.843)$ \\
\hline Median change & -1.21 & -0.66 & -0.20 & 0.29 \\
\hline Between-group comparisons ${ }^{\mathrm{a}}$ & - & 0.0468 & 0.0002 & 0.0500 \\
\hline \multicolumn{5}{|l|}{ BREEZE-AD2 } \\
\hline Sample size & 19 & 72 & 165 & 13 \\
\hline Mean (SD) at baseline & $-1.27(0.700)$ & $-0.70(0.814)$ & $-0.24(0.849)$ & $0.05(0.472)$ \\
\hline Median change & -1.26 & -0.60 & -0.29 & 0.00 \\
\hline Between-group comparisons ${ }^{\mathrm{a}}$ & - & 0.0069 & $<0.0001$ & 0.2670 \\
\hline \multicolumn{5}{|l|}{ BREEZE-AD5 } \\
\hline Sample size & 14 & 48 & 138 & 7 \\
\hline Mean (SD) at baseline & $-1.54(0.856)$ & $-1.05(0.739)$ & $-0.41(0.749)$ & $-0.47(1.075)$ \\
\hline Median change & -1.38 & -1.00 & -0.36 & -0.29 \\
\hline Between-group comparisons ${ }^{\mathrm{a}}$ & - & 0.1086 & $<0.0001$ & 0.6526 \\
\hline
\end{tabular}

ADSS, Atopic dermatitis sleep scale, ANOVA, analysis of variance; NRS, numeric rating scale; POEM, patient oriented eczema measure; SD, standard deviation

${ }^{\text {a }}$ Between-group comparisons. The $p$ value for the pairwise comparisons between consecutive severity groups was derived from an ANOVA assessing differences in score change between groups

underlying studies limit this validation to adult patients with moderate-to-severe $\mathrm{AD}$. Only a few patients were available in the mild group for assessing known-groups validity of each instrument using PGI-S-AD and POEM subgroups to define AD severity. The results of this study are also limited to a subset of patients who fluently spoke a language into which the assessment tool had been translated. The FDA recommends daily assessment of symptoms by patients as a shorter recall period allows for more reliable interpretation of symptom data [6]. However, while averaging scores over a 7-day period accounts for day-to-day variation in this analysis, this reduced variability may artificially increase the correlations with other measures [24]. Additionally, a similar study of itch severity measurement suggested a 7-day recall may be more clinically relevant [27]. Nevertheless, future studies 


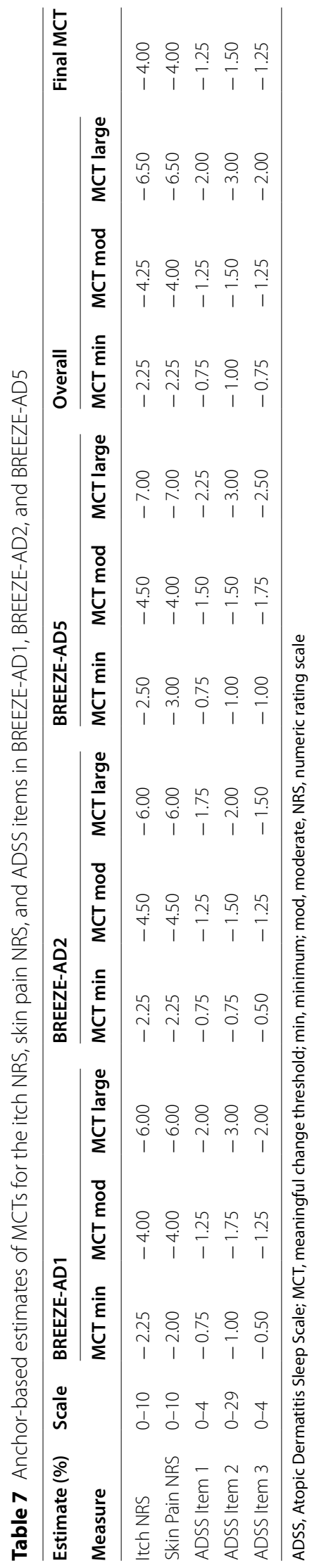


Table 8 Distribution-based estimates of MCTs for the Itch NRS, Skin Pain NRS, and ADSS items in BREEZE-AD1, BREEZE-AD2, and BREEZE-AD5

\begin{tabular}{|c|c|c|c|c|c|}
\hline \multirow[t]{2}{*}{ Measure } & \multirow[t]{2}{*}{ Study } & \multicolumn{4}{|c|}{$\begin{array}{l}\text { Distribution-based } \\
\text { estimates }\end{array}$} \\
\hline & & $0.2 \mathrm{SD}$ & $0.5 \mathrm{SD}$ & $0.8 \mathrm{SD}$ & SEM \\
\hline \multirow[t]{4}{*}{ Itch NRS (scale 0-10) } & BREEZE-AD1 & 0.42 & 1.04 & 1.67 & 0.88 \\
\hline & BREEZE-AD2 & 0.43 & 1.09 & 1.74 & 0.89 \\
\hline & BREEZE-AD5 & 0.43 & 1.09 & 1.74 & 0.92 \\
\hline & Overall & 0.43 & 1.07 & 1.72 & 0.89 \\
\hline \multirow{4}{*}{$\begin{array}{l}\text { Skin pain NRS (scale } \\
0-10 \text { ) }\end{array}$} & BREEZE-AD1 & 0.49 & 1.23 & 1.98 & 1.09 \\
\hline & BREEZE-AD2 & 0.51 & 1.27 & 2.04 & 1.06 \\
\hline & BREEZE-AD5 & 0.53 & 1.32 & 2.11 & 1.20 \\
\hline & Overall & 0.51 & 1.27 & 2.04 & 1.12 \\
\hline \multirow[t]{4}{*}{ ADSS item 1 (scale 0-4) } & BREEZE-AD1 & 0.22 & 0.54 & 0.86 & 0.49 \\
\hline & BREEZE-AD2 & 0.22 & 0.56 & 0.90 & 0.49 \\
\hline & BREEZE-AD5 & 0.24 & 0.60 & 0.95 & 0.52 \\
\hline & Overall & 0.23 & 0.57 & 0.90 & 0.50 \\
\hline \multirow[t]{4}{*}{ ADSS item 2 (scale 0-29) } & BREEZE-AD1 & 0.93 & 2.34 & 3.74 & 1.39 \\
\hline & BREEZE-AD2 & 0.46 & 1.15 & 1.85 & 1.31 \\
\hline & BREEZE-AD5 & 0.58 & 1.45 & 2.32 & 0.82 \\
\hline & Overall & 0.66 & 1.65 & 2.64 & 1.17 \\
\hline \multirow[t]{4}{*}{ ADSS item 3 (scale 0-4) } & BREEZE-AD1 & 0.19 & 0.47 & 0.76 & 0.48 \\
\hline & BREEZE-AD2 & 0.19 & 0.49 & 0.78 & 0.52 \\
\hline & BREEZE-AD5 & 0.19 & 0.47 & 0.76 & 0.51 \\
\hline & Overall & 0.19 & 0.48 & 0.77 & 0.50 \\
\hline
\end{tabular}

ADSS, Atopic Dermatitis Sleep Scale; MCT, meaningful change threshold; min, minimum; mod, moderate, NRS, numeric rating scale

are warranted to assess correlations between the Itch NRS, Skin Pain NRS and ADSS, which may further support the use of the three separate instruments in clinical practice.

\section{Conclusions}

The results of this study demonstrate that the Itch NRS, Skin Pain NRS, and ADSS are highly reliable, valid, and responsive measures of symptoms that are important to patients with $\mathrm{AD}$. In addition, each $\mathrm{PRO}$ is able to measure clinically important symptom changes in these patients. These findings support the use of these PRO instruments in clinical trials of patients with moderateto-severe $\mathrm{AD}$

\footnotetext{
Abbreviations

AD: Atopic dermatitis; ADSS: Atopic dermatitis sleep scale; ANCOVA: Analysis of covariant; ANOVA: Analysis of variance; BSA: Body surface area; DLQI: Dermatology life quality index; EASI: Eczema area and severity index; FDA: Food and drug administration; ICC: Intra-class correlation coefficients; IGA: Investigator global assessment; ITT: Intent-to-treat; MCT: Meaningful change thresholds; NRS: Numeric rating scale; PGI-S-AD: Patient global impression of severity-atopic dermatitis; POEM: Patient oriented eczema measure; PRO: Patient-reported outcome; QoL: Quality of life; SEM: Standard error
}

measurement; SD: Standard deviation; SRM: Standardized response mean; VIGA-AD: Validated investigator global assessment for atopic dermatitis.

\section{Acknowledgements}

Medical writing and editorial support were provided by Amy Ellinwood, MPH, Ph.D., and Santanu Bhadra, Ph.D., of Eli Lilly and Company.

\section{Authors' contributions}

JIS, AD, LS, JPT, BK, GY, FPN, PCG, HAD and LFE made substantial contributions to conception and design, or acquisition of data, or analysis and interpretation of data. All authors were involved in drafting the manuscript or revising it critically for important intellectual content and gave final approval of the version to be published.

\section{Funding}

This study was funded by Eli Lilly and Company.

\section{Availability of data and materials}

The datasets generated and/or analyzed during the current study are not publicly available due to individual data privacy but may be available from the corresponding author on reasonable request. Use of the three measures can be requested from copyright@lilly.com.

\section{Declarations}

\section{Ethics approval and consent to participate}

Each study was conducted with informed consent, under institutional review board approval, and in accordance with the Declaration of Helsinki (ClinicalTrials.gov numbers NCT03334396 [AD1], NCT03334422 [AD2], and NCT03435081 [AD5]).

\section{Competing interests}

JIS has received honoraria as a consultant and/or advisory board member for Abbvie, Afyx, Arena, Asana, Bluefin, Boehringer-Ingelheim, Celgene, Dermavant, Dermira, Eli Lilly, Galderma, GlaxoSmithKline, Incyte, Kiniksa, Leo, Luna, Menlo, Novartis, Pfizer, RAPT, Regeneron, Sanofi; speaker for Regeneron, Sanofi; institution received grants from Galderma. AD, LS and FN are employees of Eli Lilly and Company and may hold stock and/or stock options in the company. JPT reports personal fees from Pfizer, personal fees from Eli Lilly \& Co, personal fees from Abbvie, personal fees from LEO Pharma, grants and personal fees from Regeneron, grants and personal fees from Sanofi-Genzyme, outside the submitted work. GY has been on advisory boards for and received honoraria from Sanofi and Regeneron Pharmaceuticals, Inc. TREVI, Pfizer, Novartis, Eli Lilly, Kiniksa, LEO, Galderma, Kiniksa, GSK, and his research has been funded by Pfizer, Galderma, Novartis, LEO, Kinksa, Sanofi Regeneron and Sun Pharma. LFE has received honoroaria for his work as a consultant for Abbvie, Dermavant, Dermira, Leo, Eli Lilly, Novartis, Regeneron, Sanofi-Genzyme and Ortho Dermatology, been an investigator/received grants for Abbvie, Galderma Laboratories, Ortho Dermatology and Pfizer. BK reports personal fees from AbbVie, personal fees from Almirall, personal fees from Boehringer Ingelheim, grants and personal fees from Cara Therapeutics, personal fees from AstraZeneca, personal fees from Menlo Therapeutics, personal fees from Regeneron, personal fees from Sanofi Genzyme, grants and personal fees from LEO Pharma, personal fees from Trevi Therapeutics, personal fees from Daewoong, personal fees from OM Pharma, personal fees from Incyte, personal fees from Amagma, personal fees from Maruho, outside the submitted work; In addition, BK has a patent on JAK inhibitors for chronic itch pending to None. PCG and HAD report no conflict of interest. Fabio P. Nunes was an employee of Eli Lilly and Company, Indianapolis, Indiana, USA at the time of conducting this study. Currently he is an employee of Janssen Pharmaceutical Companies of Johnson \& Johnson, Raritan, New Jersey, USA.

\section{Author details}

${ }^{1}$ George Washington University, Washington, DC, USA. ${ }^{2}$ Lilly Corporate Center, Eli Lilly and Company, Indianapolis, IN 46285, USA. ${ }^{3}$ Bispebjerg Hospital, University of Copenhagen, Copenhagen, Denmark. ${ }^{4}$ Pied Piper Consulting, LLC, St. Louis, MO, USA. ${ }^{5}$ Miller School of Medicine, University of Miami, Miami, $\mathrm{FL}$, USA. ${ }^{6}$ Clinical Outcomes Solutions, Chicago, IL, USA. ${ }^{7}$ Clinical Outcomes Solutions, Folkestone, Kent, UK. ${ }^{8}$ University of California San Diego, San Diego, CA, USA. ${ }^{9}$ Rady Children's Hospital, San Diego, CA, USA. 
Received: 22 January 2021 Accepted: 4 October 2021

Published online: 23 October 2021

\section{References}

1. Lifschitz C. The impact of atopic dermatitis on quality of life. Ann Nutr Metab. 2015;66(Suppl 1):34-40.

2. Vakharia PP, Chopra R, Sacotte R, Patel KR, Singam V, Patel N, et al. Burden of skin pain in atopic dermatitis. Ann Allergy Asthma Immunol. 2017:119(6):548-52.

3. Hanifin JM, Thurston M, Omoto M, Cherill R, Tofte SJ, Graeber M. The eczema area and severity index (EASI): assessment of reliability in atopic dermatitis. EASI Evaluator Group Exp Dermatol. 2001;10(1):11-8.

4. Futamura M, Leshem YA, Thomas KS, Nankervis H, Williams HC, Simpson EL. A systematic review of Investigator Global Assessment (IGA) in atopic dermatitis (AD) trials: Many options, no standards. J Am Acad Dermatol. 2016:74(2):288-94.

5. Simpson E, Bissonnette R, Eichenfield LF, Guttman-Yassky E, King B, Silverberg Jl, et al. The Validated Investigator Global Assessment for Atopic Dermatitis (vIGA-AD): The development and reliability testing of a novel clinical outcome measurement instrument for the severity of atopic dermatitis. J Am Acad Dermatol. 2020;83(3):839-46.

6. US-FDA. Guidance for Industry: Patient-Reported Outcome Measures: Use in Medical Product Development to Support Labeling Claims 2009 [updated December 2009. https://www.fda.gov/downloads/drugs/guida nces/ucm 193282.pdf.

7. Newton L, DeLozier AM, Griffiths PC, Hill JN, Hudgens S, Symonds T, et al. Exploring content and psychometric validity of newly developed assessment tools for itch and skin pain in atopic dermatitis. J Patient Rep Outcomes. 2019;3(1):42

8. Simpson EL, Lacour JP, Spelman L, Galimberti R, Eichenfield LF, Bissonnette $\mathrm{R}$, et al. Baricitinib in patients with moderate-to-severe atopic dermatitis and inadequate response to topical corticosteroids: results from two randomized monotherapy phase III trials. Br J Dermatol. 2020;183(2):242-55.

9. Simpson EFS, Silverberg J, Zirwas E, Han G, Guttman-Yassky E, Marnell D, Bissonnette R, Waibel J, Nunes F, DeLozier A, Angle R, Holzwarth K, Gold blum O, Zhong J, Papp K. Efficacy and safety of baricitinib in moderateto-severe atopic dermatitis: Results from a randomized, double-blinded placebo-controlled phase 3 clinical trial (BREEZE-AD5). Revolutionizing Atopic Dermatitis, 5 April 2020. Br J Dermatol. 2020;183(4):e94-121.

10. Finlay AY, Khan GK. Dermatology Life Quality Index (DLQI) — a simple practical measure for routine clinical use. Clin Exp Dermatol. 1994;19(3):210-6.

11. Charman CR, Venn AJ, Ravenscroft JC, Williams HC. Translating PatientOriented Eczema Measure (POEM) scores into clinical practice by suggesting severity strata derived using anchor-based methods. $\mathrm{Br}$ J Dermatol. 2013;169(6):1326-32.
12. Outcomes and Psychometric Summit. Clinical Outcomes Solutions, C-Path PRO Consortium partner led Meeting Tucson, Arizona 2015.

13. Litwin M. How to measure survey reliability and validity. 7th ed. Thousand Oaks: Sage Publications; 1995

14. Nunnally J. The assessment of reliability. In: Bernstein I, editor. Psychometric theory. New York: McGraw Hill; 1994. p. 248-92.

15. Vaz S, Falkmer T, Passmore AE, Parsons R, Andreou P. The case for using the repeatability coefficient when calculating test-retest reliability. PLoS ONE. 2013:8(9):e73990.

16. Cohen J. Statistical power analysis for the behavioral sciences. 2nd ed. New York: Lawrence Erlbaum Associates; 1988.

17. Cronbach $L$ J. Coefficient alpha and the internal structure of tests. Psychometrika. 1951;16(3):297-334.

18. Coon CD, Cook KF. Moving from significance to real-world meaning: methods for interpreting change in clinical outcome assessment scores. Qual Life Res. 2018;27(1):33-40.

19. Revicki D, Hays RD, Cella D, Sloan J. Recommended methods for determining responsiveness and minimally important differences for patientreported outcomes. J Clin Epidemiol. 2008;61(2):102-9.

20. Kazis LE, Anderson JJ, Meenan RF. Effect sizes for interpreting changes in health status. Med Care. 1989;27(3 Suppl):S178-89.

21. Heeren T, D'Agostino R. Robustness of the two independent samples t-test when applied to ordinal scaled data. Stat Med. 1987;6(1):79-90.

22. McLeod LD, Coon CD, Martin SA, Fehnel SE, Hays RD. Interpreting patientreported outcome results: US FDA guidance and emerging methods. Expert Rev Pharmacoecon Outcomes Res. 2011;11(2):163-9.

23. Kimball AB, Naegeli AN, Edson-Heredia E, Lin CY, Gaich C, Nikai E, et al. Psychometric properties of the Itch Numeric Rating Scale in patients with moderate-to-severe plaque psoriasis. Br J Dermatol. 2016;175(1):157-62.

24. Yosipovitch G, Reaney M, Mastey V, Eckert L, Abbe A, Nelson L, et al. Peak Pruritus Numerical Rating Scale: psychometric validation and responder definition for assessing itch in moderate-to-severe atopic dermatitis. $\mathrm{Br}$ J Dermatol. 2019;181(4):761-9.

25. Silverberg J. Associations between atopic dermatitis and other disorders. F1000Res. 2018;7:303.

26. Kunz B, Oranje AP, Labrèze L, Stalder JF, Ring J, Taïeb A. Clinical Validation and Guidelines for the SCORAD Index: Consensus Report of the European Task Force on Atopic Dermatitis. Dermatology. 1997;195(1):10-9.

27. Silverberg JI, Lai JS, Patel KR, Singam V, Vakharia PP, Chopra R, et al. Measurement properties of the Patient-Reported Outcomes Information System (PROMIS((R))) Itch Questionnaire: itch severity assessments in adults with atopic dermatitis. Br J Dermatol. 2020;183:891-8.

\section{Publisher's Note}

Springer Nature remains neutral with regard to jurisdictional claims in published maps and institutional affiliations.

Ready to submit your research? Choose BMC and benefit from

- fast, convenient online submission

- thorough peer review by experienced researchers in your field

- rapid publication on acceptance

- support for research data, including large and complex data types

- gold Open Access which fosters wider collaboration and increased citations

- maximum visibility for your research: over 100M website views per year

At BMC, research is always in progress.

Learn more biomedcentral.com/submissions 